\title{
La reestructuración de la Armada Argentina entre el final del siglo XX y principios del XXI.
}

\author{
A reestruturação da Marinha Argentina entre o final do século XX e os \\ começos do século XXI.
}

\author{
The restructuring of the Argentina Navy between the end of the \\ twentieth century and early twenty-first.
}

Germán Soprano ${ }^{1}$

RESUMO

A definição de uma política de defesa nacional e segurança interior na democracia, criou condições para avançar no processo de reestruturação da Marinha Argentina, apresentando alterações em sua organização e funções. Este artigo faz alvo neste processo de análise, por um lado, na relação entre as definições de política de defesa e a configuração do instrumento militar naval entre o final do séculoXXe início do século XXI; e, por outro lado, compreendendo o seu desenvolvimento no caso de dois componentes desta força: o corpo de fuzileiros navais e a divisão de patrul hado marítimo.

Palavras-chave: Política de defesa. Reestruturação. Marinha Argentina. Corpo de fuzileiros navais. Patrulhado marítimo.

\section{ABSTRACT}

The definition of a policy of national defense and internal security in democracy, created conditions to advance in the process of restructuring of the Argentina Navy, introducing changes in its organization and functions. In this article we will focus this process analyzing, on the one hand, the relationship between the definitions of defense policy and the configuration of naval military instrument between the end of the twentieth century and early twenty-first century; and, on the other hand, understanding their development in the case of two components of the force: the marine corps and the division of maritime patrol.

Keyword: Defense policy. Restructuring. Argentina Navy. Maritime patrol. Marine corps.

\footnotetext{
${ }^{1}$ Doctor en Antropología Social. Magister en Sociología. Profesor en Historia. Investigador del CONICET y Profesor en la Universidad Nacional de La Platay la Universidad Nacional de Quilmes (Argentina). En esta última universidad es director del proyecto de investigación: "Política de defensa y reestructuración de las Fuerzas Armadas Argentinas entre fines del siglo XX y principios del XXI. Cambios, continuidades y desafíos”. e-mail: gsoprano69@gmail.com.
} 


\section{Introducción}

La definición de una política de Defensa nacionaly de Seguridad interior en democracia creó condiciones para avanzar en un proceso de reestructuración de la Armada Argentina, introduciendo cambios en su organización y funciones. En este artículo enfocaremos ese proceso analizando, por un lado, las relaciones existentes entre las definiciones de la política de Defensa y el diseño de instrumento militar naval entre fines del siglo XX y principios del siglo XXI; y, por otro lado, comprendiendo su desarrollo en el caso de dos componentes de esa Fuerza: la Infantería de Marina y la División de Patrullado Marítimo.

La elección de esos dos casos tiene por objeto profundizar en algunas características específicas de esa reestructuración en estos dos componentes de la Armada: el primero por ser uno fuertemente afectado por los cambios; el segundo por estar relacionado con el privilegio en los hechos otorgado a una misión no específica para una marina de guerra cual es control de la soberanía sobre el mar jurisdiccional contra el ejercicio de la pesca ilegal.

Abordaremos esta cuestión a través de documentos oficiales producidos por el Ministerio de Defensa y la Armada Argentina y mediante registros de trabajo de campo y entrevistas producidas en una etnografía realizada en el año 2008 en el marco del Observatorio Sociocultural de la Defensa establecido por la Universidad Nacional de Quilmes y el Ministerio de Defensa, con dirección de Sabina Frederic. Esa investigación implicó trabajo de campo etnográfico en diversas unidades operativas e institutos educativos del Ejército, Armada y Fuerza Aérea, entrevistas semi-estructuradas, y aplicación de una encuesta a unos 1.400 oficiales y suboficiales en actividad. El equipo estaba conformado por tres antropólogos sociales (Sabina Frederic, Laura Masson y Germán Soprano) y una asistente formada en ciencias sociales (Marina Martínez Acosta). En ocasiones el trabajo de campo se hizo de a dos personas y otras individualmente. Como resultado del convenio debíamos producir para el Ministerio de Defensa un diagnóstico empírico sobre las configuraciones socio-profesionales de las Fuerzas Armadas, así como la identificación de las percepciones y experiencias de los militares acerca de las mismas. ${ }^{2}$

\footnotetext{
${ }^{2}$ Resultados de esta investigación fueron presentados en el libro: Frederic, Masson y Soprano (2015).
} 


\section{Definiciones políticas y marco normativo de la Defensa nacional en democracia}

La sanción de la Ley 23.554 de Defensa Nacional en 1988 expresó un consenso entre los partidos políticos mayoritarios en torno de definiciones básicas para la política de Defensa en democracia que postulaban una distinción taxativa entre Defensa nacional y Seguridad interior, asignando misiones a las Fuerzas Armadas respecto de la primera y a las Fuerzas de Seguridad federales y provinciales en relación con la segunda. Dicho marco normativo fue completado con la sanción por el Congreso de la Nación de las Leyes 24.059 de Seguridad Interior de 1991, 24.429 de Servicio Militar Voluntario de 1994, 24.948 de Reestructuración de las Fuerzas Armadas de 1998, y 25.520 de Inteligencia Nacional de 2001. ${ }^{3}$

En correspondencia con esta taxativa diferenciación entre Defensa nacionaly Seguridad interior, el decreto 660 de 1996 transfirió la Prefectura Naval, Gendarmería Nacional y la Dirección Nacional de Defensa Civil desde el Ministerio de Defensa hacia el Ministerio del Interior. Hasta 1984 la Prefectura Naval y la gendarmería Nacional eran Fuerzas de Seguridad dependientes de la Armada y el Ejército, respectivamente; ese año pasaron a depender del Ministerio de Defensa. La Ley de Seguridad Interior confirmó esa inscripción orgánica, pero habilitó una relación de dependencia funcional respecto del Ministerio del Interior. En 1996 ambas Fuerzas fueron transferidas orgánica y funcionalmente a este último Ministerio. En la actualidad -y como producto de cambios en los Ministerios Nacionales- dependen del Ministerio de Seguridad junto con la Policía Federal y la Policía de Seguridad Aeroportuaria; esta última creada en 2005 tras la supresión de la Policía Aeronáutica Nacional -que había sido creada por la Fuerza Aérea en 1977.

Ahora bien, la coherencia y sistematicidad de ese ordenamiento normativo se vio vulnerada o contestada recurrentemente desde la década de 1990 hasta el presente por sectores de la dirigencia política y la conducción militar que procuraron introducir diversas modalidades de securitización de la Defensa nacional y su instrumento militar, o bien profundizar la militarización de la agenda de Seguridad interior o pública. ${ }^{4}$

3 Para un análisis de este ordenamiento jurídico véase: Ugarte (2004), Montenegro (2007). Estas iniciativas se sistematizaron en el documento denominado Modelo Argentino de Modernización del Sistema de Defensa del año 2009. Asimismo, ese marco normativo se completó con la sanción de la Ley 26.394 de 2008 que estableció un nuevo régimen de justicia y disciplina militar y, más recientemente, la Ley 27.126 de Creación de la Agencia Federal de Inteligencia. ${ }^{4}$ La Ley de Defensa Nacional se reglamentó sólo dieciocho años después de su sanción con la aprobación de los decretos 727 de Reglamentación de la Ley de Defensa Nacional (2006), 1.691 Directiva sobre Organización y Funcionamiento de las Fuerzas Armadas (2006), 1.729 definiendo el Ciclo de Planeamiento dela Defensa Nacional (2007),788 sobrelas Estructuras Organizativas de la Secretarías del Ministerio de Defensa (2007) y 1.451 modificando el Organigrama y Objetivos del Ministerio (2008), 1.714 fijando la Directiva de Política de Defensa Nacional (2009) y 1.736 estableciendo el Procedimiento de promoción, permanencia en el grado o eliminación del Personal Militar dentro dela cate goría de Oficial Superior(2009). También se impulsó en esos años la desmilitarización de funciones y organismos otrora dependientes de las Fuerzas Armadas, que pasaron a la órbita del Ministerio de Defensa (Servicio Meteorológico Nacional, Servicio de Hid rografía 
La Ley de Defensa Nacional y su reglamentación definió una concepción "defensiva", "autónoma" y "cooperativa" que -según lo establecido en el decreto 727 reglamentario- tenía por objetivo conjurar "agresiones de origen externo perpetradas por Fuerzas Armadas pertenecientes a otro/s Estado/s" y de acuerdo con la Resolución 3.314 (del año 1974) de la Organización de las Naciones Unidas. El recurso a esos tres principios suponía que el país debía desarrollar capacidades "defensivas" y "autónomas" efectivas contra potenciales amenazas externas, complementándolas con el recurso a la "coopera ción" con otros países, especialmente, aquellos comprendidos en el ámbito regional del Cono Sur y Suramericano.

Según el artículo 3 del decreto 727, el sistema de Defensa nacional no podía contemplar en su doctrina, planificación, adiestramiento, adquisiciones de equipos y/o medios y en sus actividades de inteligencia, cualquier "hipótesis, supuestos y/o situaciones pertenecientes al ámbito de la Seguridad interior". En consecuencia, esta última política pública quedó fuera del alcance de las Fuerzas Armadas, con excepción de aquellas situaciones previstas por la Ley de Seguridad Interior que prescriben la intervención de las Fuerzas Armadas en: a) operaciones de apoyo logístico a la Seguridad interior por requerimiento de un comité de crisis y explícita disposición del Ministro de Defensa; b) operaciones destinada a la preservación de las Fuerzas Armadas y de restablecimiento del orden en jurisdicción militar en caso de atentado a dicha jurisdicción en tiempos de paz; c) operaciones que empeñen elementos de combate a requerimiento del Presidente y previo establecimiento del estado de sitio. $^{5}$

Por su parte, el Decreto 1.691 de 2006 -denominado Directiva sobre Organización y Funcionamiento de las Fuerzas Armadas- delimitó como "misión principal" de las Fuerzas Armadas "conjurar y repeler toda agresión externa militar estatal", y cuatro "misiones subsidiarias" relacionadas con su participación en operaciones multilaterales de Naciones Unidas, operaciones de apoyo a la Seguridad interior previstas por la Ley 24.059 de Seguridad Interior, tareas de apoyo a la comunidad nacionalo de "países amigos", y en la construcción de un sistema de Defensa subregional.

Naval, Instituto Geográfico Nacional, entre otros)y del Ministerio de Planificación Federal, Inversión Pública y Servicios o del Ministerio del Interior y Transporte (Administración Nacional de Aviación Civil). La reglamentación de la Ley de Defensa Nacional, no obstante, no obturó las recurrentes tentativas por implicar a las Fuerzas Armadas en asuntos de orden interno y Seguridad interior vulnerando con ello el marco normativo en vigencia hasta el presente.

${ }^{5}$ Efectuamos una revisión más exhaustiva sobre esos cambios políticos y normativos que orientaron la política de Defensa desde la reglamentación de la ley homónima en el capítulo 1 del libro: Lafferriere y Soprano (2015). 


\section{Diseño de fuerza de la Armada Argentina en el cambio del siglo XX al XXI}

¿En qué medida la definición de esa política y marco normativo de la Defensa nacional en democracia orientó la restructuración o reformas en las Fuerzas Armadas y, en particular, en el instrumento militar naval? Su incidencia en este último revela un impacto relativo. Por un lado, pueden reconocerse fenómenos expresivos de cambios:

- La intervención de la Armada Argentina (y de las otras Fuerzas Armadas) en los asuntos de Seguridad interior fue política y legalmente abandonada, aún cuando en contra de esas prescripción en marzo de 2006 se hizo público un hecho crítico: se abrió una causa judicial por espionaje a raíz de actividades de inteligencia ilegales desarrolladas por personal militar en la Base Aeronaval "Almirante Zar" localizada en la ciudad patagónica de Trelew (provincia de Chubut), por la cual fueron procesados oficiales y suboficiales que realizaban tareas de espía sobre dirigentes políticos, sindicales y sociales. ${ }^{6}$

- La supresión de las históricas hipótesis de conflicto vecinales mantenidas por la Argentina con Chile y Brasil, inaugurando una etapa de construcción de confianza mutua y cooperación entre la Armada Argentina, la de Chile y la Marina del Brasil. Asimismo, con la Armada de Chile se integró la Patrulla Antártica Combinada y con elementos de las tres Fuerzas Armadas Argentinas y de Chile se conformó en 2006 la Fuerza de Paz Combinada-Conjunta "Cruz del Sur". ${ }^{7}$ También los cambios estuvieron asociados al abandono de un esquema de Defensa hemisférica propio del escenario internacional de la "Guerra Fría", continuando la realización de los ejercicios combinados UNITAS en los que se participaba con las fuerzas nava les de la región con el liderazgo de la Marina de los Estados Unidos. ${ }^{8}$

- La baja y desmantelamiento del portaviones ARA "25 de Mayo" en 1997 y el reagrupamiento y reducción cuantitativa de unidades y personal de infantería de marina pueden considerarse hitos de ese cambio, pues demostraron voluntad por renunciar a capacidades aeronavales y anfibias que garantizasen la proyección del

\footnotetext{
${ }^{6}$ La causa judicial se había originado por denuncia de un cabo de la Armada, presentada ante el Centro de Estudios Legales y Sociales-CELS, una organización no gubernamental de promoción y defensa de los derechos humanos creada en 1979y dirigida entonces por el periodista Horacio Verbitsky.

${ }^{7}$ Sobre la Patrulla Antártica Combinada, véase: Martín (2013). En relación con la Fuerza de Paz Combinada-Conjunta "Cruz del Sur": (VÁRNAGY,2010). Sobre el rol dela educación de oficiales en la profundización del accionar militar conjunto entre las Armadas de Argentina y Chile: Velázquez Pacheco (2010).

${ }^{8}$ Cabe destacar que aun existiendo esas hipótesis de conflicto las fuerzas navales de Argentina, Brasil y Chile participaban de los ejercicios navales combinados UNITAS liderados desde 1960 por los Estados Unidos.
} 
poder naval del país en aguas alejadas de las jurisdiccionales. ${ }^{9}$ Sin embargo -y aún no desconsiderando el peso de estos factores- debería destacarse también la agencia de otra causa decisiva: los recortes en el presupuesto en el área de Defensa producidos en democracia y, particularmente, en el gasto público con las políticas neoliberales de los años 1990-2001 determinaron una mengua significativa de recursos que tuvo efectos estructurales en el sostenimiento de los medios de la Armada, el Ejército y la Fuerza Aérea Argentina.

- La participación de la Armada Argentina en misiones internacionales asumiendo compromisos de la Argentina en el mantenimiento de la seguridad global o regional: a) Bajo mandato del Consejo de Seguridad de la ONU en la "guerra del Golfo" contra Iraq en 1990-1991. ${ }^{10}$ b) Y bajo mandato de Naciones Unidas en las misiones de paz mencionadas a continuación: Grupo de Observadores de Naciones Unidas en Centroamérica- ONUCA entre 1990 y 1991; ${ }^{11}$ Misión de Observación de Naciones Unidas para Iraq y Kuwait-UNIKOM, ${ }^{12}$ Misión de las Naciones Unidas para el Referendum del Sahara Occidental-MINURSO desde 1991; ${ }^{13}$ Misión de Naciones Unidas en Haití-UNMIH entre 1993-1994; ${ }^{14}$ Organismo de Naciones Unidas para Vigilancia de la Tregua-UNTSO en distintas localizaciones en Medio Oriente (canal de Suez, Altos del Golán, Sinaí, Beirut, Gaza) desde 1992; ${ }^{15}$ Fuerza de la ONU para el Mantenimiento de la Paz en Chipre-UNFICYP desde 1994; Fuerza de la ONU para el Mantenimiento de la Paz en Chipre-UNFICYP desde 1993; ${ }^{16}$ y Misión de Estabilización de las Naciones Unidas en Haití-MINUSTAH desde 2004. ${ }^{17}$

- La completa profesionalización del personal con la incorporación de tropa voluntaria en reemplazo de los soldados/marineros conscriptos a partir de 1995, tras la suspensión de la Ley de Servicio Militar Obligatorio y la sanción de la Ley de Servicio

\footnotetext{
${ }^{9}$ El portaviones ARA “25 de Mayo” fue adquirido porla Argentina en 1968 e incorporado a la Flota de Mar al año siguiente en reemplazo del portaviones ARA “Independencia". Se trataba de un portaviones ligero de la Clase Colossus construido entre 1942-1943 en Gran Bretaña y modernizado tras la Segunda Guerra Mundial en Holanda. Fue dado de baja en 1997 y desguazado poco después como chatarra en la India.

${ }^{10}$ La Armada Argentina remitió en ocasión de la "guerra del Golfo" dos grupos de tareas: el destructor ARA Almirante Brown y la corbeta Spiro integrando el grupo de tareas 88.0, y la corbeta ARA Rosales y el transporte ARA Bahía San Blas conformando el grupo de tareas 88.1.

11 En la ONUCA con cuatro Lanchas Patrulleras destinadas a resguardar el cumplimiento de compromisos asumidos por los gobiernos de Costa Rica, El Salvador, Guatemala, Honduras y Nicaragua.

${ }^{12}$ UNIKOM fue la misión de Naciones Unidas desplegada tras la primera guerra del Golfo.

${ }^{13}$ En la MINURSO se ha intervenido con observadores militares. http://www.armada.mil.ar/pag.asp? idItem=283.

${ }^{14}$ En el marco de la UNMIH se participó en los Operativos Talos con las corbetas ARA Granville, ARA Guerrico y ARA Drummond.

${ }^{15}$ En UNTSO se ha intervenido con observadores militares. Previamente la Argentina había enviado observadores entre 1969 y 1982. http://www.armada.mil.ar/pag.asp?idItem=284.

${ }^{16}$ En la UNFICYP participa con efectivos de infantería de marina que integran la Compañía "Charlie” de la Fuer za de Tarea Argentina, el pelotón de Ingenieros Anfibio y la Sección de Servicios. http://www.armada.mil.ar/pag.asp?idItem=281. ${ }^{17}$ En la MINUSTAH la Armada Argentina ha contribuido con personal de infantería de marina y algunos oficiales navales cada cuatro años, alternándose principalmente con personal del Ejército Argentino.
} 
Militar Voluntario en 1994; y la incorporación de las mujeres como oficiales del cuerpo comando desde 2002. ${ }^{18}$

Ahora bien, por otro lado, el diseño de fuerza de la Armada Argentina no fue -en otros sentidos- formalmente modificado en esos años. Tal ha sido el caso de su configuración en tres Áreas Navales definidas estratégicamente por las características de los ambientes específicos en los que se empeñaba el instrumento militar naval. Esa persistencia formal de diseños de fuerza heredados de etapas precedentes del siglo XX, no obstante, se encontraba sustancialmente afectada en el cambio del siglo XX al XXI por una significativa pérdida de capacidades militares producto de importantes reducciones presupuestarias que afectaron tanto la renovación de medios como las posibilidades operativas de sus elementos. Téngase presente al respecto que la última incorporación relevante de medios navales adquiridos por la Armada Argentina -como veremos- ocurrió en la década de 1980 tras la "guerra de Malvinas".

Entre fines del siglo XIX y principios del siglo XX se resolvió un importante debate estratégico en el Estado argentino con relación a la Armada, entre quienes, por un lado, eran partidarios del desarrollo de una marina fluvial centrada la cuenca del Río de la Plata y, por otro, aquellos que postulaban la necesidad de una marina oceánica que proyectara su poder en el Mar Argentino, el Atlántico Sur y la Antártida (ROJAS; MEDRANO, 1978; OYARZÁBAL, 2005). Esa proyección favoreció la presencia de la Armada en el litoral de la Patagonia y en la Tierra del Fuego (ALBARRACÍN, 1976; DESTÉFANI, 1978). Conforme esa definición estratégica, en 1898 comenzó a construirse la Base Naval Puerto Belgrano en las inmediaciones de la localidad de Punta Alta, en el sur de la provincia de Buenos Aires (TRIADÓ, 1991). No obstante, esto no implicó que la Armada renunciara a su presencia en la cuenca del Río de la Plata (ROJAS, 1974) decidiéndose, además, la creación en 1916 del Parque de Aerostación y Escuela de Aviación de la Armada en el Fuerte Barragán (Ensenada, provincia de Buenos Aires) y, luego, su traslado y puesta en funcionamiento en 1926 en la Base Aeronaval Punta Indio (en la localidad homónima en la provincia de Buenos Aires) con el objetivo de asegurar el control del acceso a su estuario y defender de potenciales amenazas externas el área metropolitana de la ciudad de Buenos Aires, así como llevar a cabo las actividades de la Escuela de Aviación y de Aerostación Naval. Desde entonces la Armada se configuró como una fuerza militar desplegada en el Atlántico Sur y en los grandes ríos navegables de la cuenca del Río de la Plata. ${ }^{19}$

Las unidades de la Armada localizadas en la cuenca del Río de la Plata dependían del Área Naval Fluvial, creada en 1974, cuyo comando tenía sede en la ciudad bonaerense de Zárate a

\footnotetext{
${ }^{18}$ Las mujeres ya se había integrado como suboficiales del cuerpo comando desde 1980.

${ }^{19}$ Conforme el punto de vista del contraalmirante (R) Roberto Pertusio(2005), el poder naval fue concebido históricamente en la Argentina del siglo XX como uno definido por una "actitud estratégica defensiva". Ciertamente, dicha definición no era incompatible con la disposición de elementos netamente ofensivos en el nivel táctico -como la fuerza de submarinos, infantería de marina y escuadrillas aeronavales de ataque embarcadas en portaaviones u operando desde tierra.
} 
principios del siglo XXI. Se extendía desde el Destacamento Naval Posadas (provincia de Misiones) hasta la Base Aeronaval Punta Indio (provincia de Buenos Aires), ${ }^{20}$ comprendiendo además la Base Naval Zárate, el Apostadero Naval (Dársena Norte) y el Comando de Transporte Naval y el Comando Naval Antártico (Dársena Sur) en la Ciudad Autónoma de Buenos Aires, y el Comando de Sostén Logístico de Movilización Aeronaval y la Segunda Escuadrilla de Sostén Logístico de Movilización en Ezeiza (provincia de Buenos Aires). ${ }^{21}$ La sede del Comando del Área Naval Fluvial estaba en la Base Naval Zárate donde, además, tenían su asiento el Batallón de Infantería 3. La Escuadrilla de Ríos repartía sus medios entre esta última Base Naval y el Apostadero Naval de la ciudad de Buenos Aires. ${ }^{22}$

El Área Naval Atlántica se extendía desde la desembocadura del Río de la Plata en el Cabo San Antonio (provincia de Buenos Aires) hasta Comodoro Rivadavia (provincia de Chubut). Su Comando tenía asiento en la Base Naval Mar del Plata (provincia de Buenos Aires). La proyección del instrumento militar en las Áreas Naval Atlántica y Austral era prioridad -al menos en su enunciación discursiva- en la política de Defensa, pues comprometía el resguardo de la soberanía nacional en el Mar Argentino -una misión principal de la Armada. ${ }^{23}$ Eran bases y establecimientos del Área Naval Atlántica: el Arsenal Naval Azopardo (en la localidad de Azul, provincia de Buenos Aires), la Base Naval Mar del Plata (provincia de Buenos Aires), ${ }^{24}$ la Base Naval Puerto Belgrano (Punta Alta, provincia de Buenos Aires), ${ }^{25}$ la Base Aeronaval Comandante Espora (Punta Alta, provincia de Buenos Aires), ${ }^{26}$ la Base

\footnotetext{
${ }^{20}$ En la Base Aeronaval Punta Indio estaba el Comando de Fuerza Aeronaval 1 del cual dependía la Primera Escuadrilla Aeronaval de Ataque y la Escuela de Aviación Naval (con aviones Beechcraft T-34-1 “Turbo Mentor"), además de la Agrupación Aerofotográfica (con Beechcraft B200 "Super King Air").

${ }^{21}$ La Escuadrilla Naval de Ríos comprendía los Patrulleros Murature y King (construidos en la Argentina en los años 1945 y 1946), los Buques Multipropósito Ciudad de Rosario y Ciudad de Zárate (de la década de 1960 y de procedencia norteamericana, adquiridos en 1999) y la Lancha Patrullera Río Santiago (dela década de 1960). Los buques hidrográficos Cormorán y Comodoro Rivadavia (construidos en Argentina en 1964 y 1974) cumplían tareas en el Servicio de Hidrografía Naval.

${ }^{22}$ La información sobre los comandos y unidades de las Áreas Navales fue relevada conforme al Libro Blanco de la Defensa de 2010 y complementada con fuentes de la Armada Argentina.

${ }^{23}$ Del Área Naval Austral nos ocuparemos unas páginas más abajo.

24 Además del Comando del Área Naval Atlántica, en la Base Naval Mar del Plata tenía su asiento la División de Patrullado Marítimo que realizaba el patrullaje del Mar Argentino. Esta División estaba conformada por tres Corbetas Tipo A-69 (construidas en Francia): Drummond (1978), Granville(1982) y Guerrico(1978); los Avisos Alférez Sobral(1944) y Suboficial Castillo (construidos en 1944 y adquiridos a Estados Unidos en 1972 y 1994); y la Lancha Patrullera Punta Mogotes (construida en Estados Unidos en la década de 1960 e incorporada por la Armada en 1999). También tenían su asiento el Comando de la Fuerza de Submarinos con tres unidades -el submarino Salta (Clase Salta IKL-290 fabricado en Alemania 1972) y los submarinos Santa Cruz y San Juan (Clase Santa Cruz TR-170 adquiridos en 1982 y 1983); así como el buque oceanográfico Puerto Deseado(fabricado en Argentina en 1978), el Arsenal Naval Mar del Plata y la Agrupación de Buzos Tácticos.

25 La Base Naval Puerto Belgrano era sede del Comando de la Flota de Mar compuesta por la División de Destructores MEKO 360 (fabricados en Alemania): Almirante Brown (1983), Heroína (1983), La Argentina (1983) y Sarandí (1984); la División de Corbetas-Fragatas MEKO 140 (de fabricación nacional): Espora (1985), Rosales (1986), Spiro (1987), Parker (1990), Robinson(2001) y Gómez Roca (2004); y la División de Comando Naval Anfibio y Logístico que contaba con el Transporte Multipropósito Hércules (construido inicialmente en Chile y terminado en Argentina entre el año 2000 y 2003), el Aviso Teniente Olivieri (adquirido en Estados Unidos en 1981), el Buque Multipropósito Punta Alta (adquirido a Estados Unidos en el 2000), el Buque Tanque Ingeniero Krause(1981, de fabricación nacional), el Buque Logístico Patagonia (1977, adquirido en 1999 en Francia), los Buques de Transporte Canal de Beagle, Cabo de Hornos y Bahía San Blas (1978, de fabricación nacional) dependientes del Comando de Transportes Navales.

$26 \mathrm{La}$ Base Aeronaval Comandante Espora era sede del Comando de la Fuerza Aeronaval 2. La Escuadra Aeronaval 2 que comprendía la Escuadrilla Aeronaval Antisubmarina (con unidades Grumman S-2 Tracker "Turbo Tracker" y Pilatus
} 
Aeronaval Almirante Zar en la ciudad de Trelew, ${ }^{27}$ la Estación de Balizamiento Puerto Madryn y el Destacamento Naval Comodoro Rivadavia (estas últimas tres unidades en la patagónica provincia de Chubut). En Puerto Belgrano también tenía asiento la Fuerza de Infantería de Marina de la Flota de Mar-FAIF. ${ }^{28}$ De las unidades navales resta mencionar el Buque Escuela Fragata Libertad (fabricado en el país en 1963) y el Rompehielos Almirante Irízar (adquirido en Finlandia en 1978 y en reparaciones tras sufrir un incendio a bordo en abril de 2007), dependientes de la Dirección General de Educación Naval y de la Dirección Nacional del Antártico, respectivamente.

Por último, el Área Naval Austral se extendía desde Comodoro Rivadavia hasta la Isla Grande de Tierra del Fuego e Isla de los Estados. Su Comando tenía asiento en la ciudad de Ushuaia (provincia de Tierra del Fuego, Antártida e Islas del Atlántico Sur). Sus bases y establecimientos eran el Apostadero Naval Puerto Deseado, la Subzona Naval Santa Cruz y el Apostadero Naval Río Gallegos (provincia de Santa Cruz), la Fuerza de Infantería de Marina Austral-FAIA cuyo comando estaba en Ushuaia, la Base Aeronaval Río Grande (en la ciudad homónima), ${ }^{29}$ el Apostadero Naval "Luis Piedra Buena" (en la Isla de los Estados), la Base Naval "Almirante Berisso" (Ushuaia) ${ }^{30}$ y las Bases Antárticas: Orcadas, Petrel, Tte. Cámara, Decepción, Melchior.

\section{El caso de la Infantería de Marina}

De acuerdo con información institucional de la Armada Argentina, entre 1989 y 1992 el Comando de Infantería de Marina definió orientaciones para una importante "reorganización" de sus elementos, funciones y despliegues conforme al siguiente criterio:

PC6B2/H2 “Turbo Tracker), la Primera Escuadrilla Aeronaval de Helicópteros (Eurocopter AS-555SN “Fennec”), la Segunda Escuadrilla Aeronaval de Helicópteros (Sikorsky S-61 D4 "Sea King” y Agusta Sikorsky AS-61 D4 “Sea King”) y la Segunda Escuadrilla Aeronaval de Caza y Ataque (Super Étendard).

${ }^{27}$ En la Base Aeronaval Almirante Zar estaba el Comando de la Fuerza Aeronaval 3. La Escuadra Aeronaval 3 estaba integrada por la Escuadrilla Aeronaval de Exploración (Lockheed P-3 “Orion"), Escuadrilla Aeronaval de Vigilancia Marítima (Beechcraft B200 “Cormorán”) y las Escuadrillas Aeronavales 3 y 6 (Fokker F-28).

28 Fuerza de Infantería de Marina de la Flota de Mar-FAIF comprendía: el Batallón de Infantería de Marina 2, el Batallón de Artillería de Campaña 1, el Batallón de Apoyo y Comando Logístico, el Batallón Antiaéreo, el Batallón de Comunicaciones 1, el Compañía de Ingenieros Anfibios, el Batallón de Vehículos Anfibios, el Batallón de Artillería de Campaña 1 y la Agrupación Comandos Anfibios. Cabe señalar -como veremos poco más adelante- que la Infantería de Marina ha sido un componente de las Fuerzas Armadas fuertemente afectado por procesos de reestructuración.

29 De la Fuerza de Infantería de Marina Austral-FAIA dependían: el Batallón de Infantería de Marina 4 (Ushuaia) y el Batallón de Infantería de Marina 5 (Río Grande).

30 La Base Naval de Ushuaia era asiento de la Agrupación de Lanchas Rápidas que contaba con las Lanchas Rápidas Intrépida e Indómita (ambas adquiridas en Alemania en 1974), las Lanchas Patrulleras Rápidas Baradero, Barranqueras, Clorinda y Concepción del Uruguay (todas procedentes de Israel e incorporadas en 1978), la Lancha Patrullera Zurubí(de 1939, fabricación nacional) y el Aviso Gurruchaga (de 1945, adquirido a Estados Unidos en 1975). 
Un núcleo Centro que asumiría el rol principal:la Función Anfibia; que atiende a la proyección del Poder Naval a tierra. Un núcleo Sur, que asumirá la Función de Contribución al Control del Mar en la Zona Austral. Derivada de la existencia de los pasos bioceánicos y estrechos en nuestro Sur. Un núcleo Norte que asumirá la Función de Control de los Grandes Ríos de la Cuenca del Plata (ARMADA ARGENTINA, 2005, p. 38).

Ese proceso de "reorganización" -por el cual se procuraba adecuar el diseño de fuerza a las orientaciones de la política de Defensa nacional- no alcanzó resultados positivos en la perspectiva de la conducción de la Armada. En 2005 se evaluaba en una publicación oficial de la Fuerza que:

A principios de 1997 el ponderable esfuerzo realizado por el Cuerpo [de Infantería de Marina] a partir de 1993, no había logrado totalmente generar los beneficios pretendidos. Por el contrario, el amesetamiento del presupuesto de la Armada y la persistente degradación de sus medios en una estructura de gasto fuertemente comprometida en el pago de salarios, obligó una vez más a utilizar como variable de ajuste una nueva y significativa reducción del personal, particularmente de la tropa voluntaria. Ello impactó fuertemente en la estructura del Componente, y como resultado volvimos a tener organizaciones vacías, sin lo mínimo para funcionar, con medios en su mayoría obsoletos y mal mantenidos, y lo que era peor, sin expectativa alguna de modernizarlos, ni de dar un salto cualitativo en nuestra forma de empleo (ARMADA ARGENTINA, 2005, p. 38-39).

Asumiendo que la espera de un aumento significativo del presupuesto para el instrumento militar de la Defensa (más allá de lo provisto para salarios y haberes jubilatorios) era vana, la conducción naval adoptó (con resignación) la consigna: "calidad antes que cantidad". En función de ello, y considerando el escenario regional de paz y cooperación en el Cono Sur y en el escenario internacional pos-guerra Fría donde el país participaba con efectivos militares en misiones de paz, ${ }^{31}$ se propuso la adecuación de la infantería de marina a las siguientes capacidades que la fuerza debía disponer para el siglo XXI: a) capacidad de proyectar a la Armada con una "fuerza expedicionaria", considerando que para entonces la

\footnotetext{
${ }^{31}$ Debe repararse quela Infantería de Marina de la Armada Argentina desde 1993 tuvo una participación cuantitativamente significativa en los contingentes enviados a la misión de paz de Naciones Unidas en Chipre (UNFICYP).
} 
Fuerza ya no contaba con un buque anfibio polifuncional y flexible propio; b) capacidad de actuar en "conflictos de baja intensidad, en ambientes esencialmente urbanos y con alto nivel de incertidumbre", sin con ello desatender las capacidades para desarrollar operaciones anfibias "convencionales"; c) capacidad para operar en distintos ambientes geográficos respondiendo a necesidades y demandas de la defensa nacional o a otras planteadas por los compromisos internacionales asumidos por el país; d) capacidad de "interoperación combinada" con países de la región o con otros con los que se mantenga convergencias en misiones internacionales; e) capacidad de respuesta (alistamiento) inmediata a las demandas de la Defensa (ARMADA ARGENTINA, 2005, p. 39).

Estas decisiones de la conducción militar dieron lugar a un nuevo ajuste organizacional hacia fines de la década de 1990 por el cual: a) el denominado núcleo Centro se concentró Fuerza de Infantería de Marina de la Flota de Mar-FAIF comprendiendo elementos preparados para llevar a cabo el "rol anfibio": el Batallón de Infantería de Marina 2, el Batallón de Artillería de Campaña 1, el Batallón de Apoyo y Comando Logístico, el Batallón Antiaéreo, el Batallón de Comunicaciones 1, el Compañía de Ingenieros Anfibios, el Batallón de Vehículos Anfibios, el Batallón de Artillería de Campaña 1 y la Agrupación Comandos Anfibios; b) el núcleo Norte en la Base Naval Zárate integrado por el Batallón de Infantería de Marina 3 trasladado allí en 1999 desde su anterior emplazamiento en la ciudad de La Plata-y dispuesto para la realización de operaciones navales fluviales; c) el núcleo Sur en torno de las unidades de la Fuerza de Infantería de Marina Austral-FAIA: el Batallón de Infantería de Marina 5 (Río Gallegos) y el Batallón de Infantería de Marina 4 (Ushuaia), aptas para el desempeño en operaciones en la baja montaña y el monte austral y en operaciones anfibias en la región de los canales interoceánicos del extremo sur del país. ${ }^{32}$ Este proceso también implicó el desarrollo de la "aeromovilidad", esto es, la incorporación de helicópteros en las operaciones de la infantería de marina.

A fines del año 2008, durante la realización de trabajo de campo en unidades militares, un capitán de navío de infantería de marina refería a ese proceso de reestructuración producido entre fines del siglo XX y principios del XXI del siguiente modo:

En los años noventa se cerraron unas ocho unidades. Hoy sabemos que el presupuesto no va a aumentar y que tenemos que arreglarnos con menos. Con armas viejas y cuarteles dispersos. A eso se le llama proceso de modernización. Con los elementos que tenemos ni siquiera podemos completar el personal de la FAIF que debería tener tres batallones.

\footnotetext{
${ }^{32}$ El Batallón de Infantería de Marina 4 en 1968 había trasladado sus componentes desde sus emplazamientos en la ciudad de Buenos Aires, Zárate e Isla Martín García hacia la ciudad de Trelew. En 1984 fue declarado su "receso temporal" y puesto nuevamente "en actividad" entre 1988 y 1990 en la ciudad de Río Gallegos. En 2002 se dispuso su traslado a la ciudad de Ushuaia.
} 
Tenemos, por eso, que adiestrar un núcleo importante en Puerto Belgrano y enviarlos luego a Zárate, Ushuaia o Río Grande. Pero esto tiene limitaciones porque no se puede armar una unidad por módulos, con gente trasplantada de otras unidades para poder operar. Tenemos que revertir esto y poder contar con elementos hecho s de unidades ternarias: un pelotón de tres o cuatro hombres. Con tres pelotones tener un grupo. Con tres grupos una sección. Con tres secciones una compañía. Con tres compañías tres batallones. Con tres batallones una fuerza. Cada uno de esos segmentos de la organización tiene que disponer de algún grado de autosuficiencia. Nade de eso tenemos hoy. (Cuaderno de Campo Espiralado, Armada IV, nov. 2008).

Ciertamente, la expresión "a eso se le llama proceso de modernización" estaba cargada de ironía, pues con ella este oficial superior expresaba indirectamente que la reestructuración de la fuerza había obrado en esos años más como efecto de las carencias presupuestarias y las dificultades para incorporar personal, que producto de una concepción orgánica que adecuara el instrumento militar con arreglo a las necesidades de la política de Defensa. Aquel capitán de navío completaba su evaluación del negativo estado de situación de la infantería de marina destacando las dificultades crónicas que se presentaban a sus componentes desde la suspensión de la Ley de Servicio Militar Obligatorio en 1994 y la implementación desde 1995 de la Ley de Servicio Militar Voluntario. Con el escaso personal disponible -decía- los suboficiales y soldados voluntarios debían cumplir con una polifuncionalidad de roles para poder dar cuenta de las necesidades determinadas por la misión principal y las subsidiarias requeridas a las Fuerzas Armadas:

Tenemos un presupuesto muy chico, por eso somos sufridos, creativos, para poder seguir siendo operativos. Buscamos náufragos. A Sofía en Río Grande [se refería a una niña desaparecida ese año en las proximidades de esa localidad en la provincia de Tierra del Fuego]. Sofocamos incendios en el Delta. Somos muy permeables a las demandas civiles de este tipo. Cumplimos todos los roles subsidiarios: misiones de paz, integración de fuerzas subregionales con Perú y Chile, catástrofes y apoyo a países amigos. Trabajamos todos los días. En Haití nos enfrentamos con el contrabando y las drogas, con problemas de seguridad ante que con operaciones convencionales. Nos preparamos para el combate urbano que es una operación cada vez más importantey que hay que hacer evitando daños colaterales. (Cuaderno de Campo Espiralado, Armada IV, nov. 2008). 
Como destacaba este oficial superior, las misiones subsidiarias de las Fuerzas Armadas participación en misiones de paz, apoyo a la comunidad nacional y de "países amigos" ante catástrofes- demandaban recursos humanos y materiales permanentemente a la infantería de marina. Las operaciones anfibias - que constituían el rol fundamental de este componente de la Armada en cumplimiento de su misión principal en el sistema de Defensa nacionaltambién reclamaban esfuerzos de los infantes de marina, pero para su concreción disponían de medios insuficientes $\mathrm{u}$ obsoletos y estaban afectados por la escasez de personal suboficiales y, sobre todo, soldados voluntarios. ${ }^{33}$ Basta destacar, al respecto, que la Armada Argentina no disponía de un buque anfibio y, por tanto, las operaciones anfibias efectuadas en terrenos de la Base Naval de Infantería de Marina de "Baterías" -en las proximidades de Puerto Belgrano- debían realizarse simulando con los vehículos un movimiento de alejamiento desde la costa y, luego, regresar a la playa para concretar la maniobra. En consecuencia, como observaba lapidariamente un capitán de fragata infante de marina en ocasión de un ejercicio anfibio: "Nosotros tenemos gente que nunca hizo una operación de desembarco desde un buque anfibio... No entiendo por qué no compran el buque anfibio. Si sirve para operaciones de ayuda humanitaria en Haití, en inundaciones como las de Santa Fe... En una hora ahí podés evacuar mil quinientas personas!" (Cuaderno de Campo Espiralado, Armada IV, nov. 2008).

En la perspectiva de este oficial jefe, la invocación al cumplimiento de las misiones subsidiarias de las Fuerzas Armadas -como participación en misiones de paz o en tareas de apoyo a la comunidad- debía permitir a los infantes de marina alcanzar el anhelado objetivo de disponer nuevamente de un medio indispensable -el buque anfibio-para la realización de operaciones comprometidas con su misión principal. En efecto, entendía que antes que justificar el potencial empeñamiento de ese medio en la Defensa nacionaly en opera ciones militares era, por el contrario, preciso demostrar a los dirigentes políticos -con responsabilidades en la definición del presupuesto público - que dicho buque tenía relevantes usos civiles en ocasión de catástrofes que afectaban a la población del país o de "países amigos". En consecuencia, los principios que legitimaban u otorgaban reconocimiento social a la infantería de marina resultaban más de sus eventuales empleos en la Defensa civil que en la Defensa nacional.

\footnotetext{
${ }^{33}$ La dificultades para completar las estructuras orgánicas de los diferentes componentes delas unidades de infantería de marina -y más ampliamente de las Fuerzas Armadas Argentinas- tenían pro resultado una des-jerarquización de las funciones de los cabos segundos que, ante la escasez de soldados voluntarios, acababan cumpliendolos roles de combate y tareas de estos últimos.
} 


\section{El caso de la División de Patrullado Marítimo}

En el año 2008, durante el trabajo de campo etnográfico que efectué en instituciones educativas y unidades operativas de las Fuerzas Armadas, tuve oportunidad de embarcar en un buque de guerra de la División de Patrullado Marítimo -dependiente del Área Naval Atlántica y con asiento en la Base Naval Mar del Plata desde que fuera creada en el año 2001. Dicho buque realizaba la patrulla de las 200 millas del Mar Argentino. ${ }^{34}$ Se trataba de una de las unidades de la Armada por entonces más operativas, ${ }^{35}$ un "aviso", esto es, uno de buque de logístico con una dotación de unos setenta hombres. A diferencia de los destructores, fragatas y corbetas - navíos de combate y de mayor porte- navegaba buena parte del año efectuando, además, la Patrulla Antártica desde que el buque rompehielos ARA Almirante Irízar quedara inutilizado y fuera enviado a reparaciones tras un incendio ocurrido abordo en 2007. Al igual que los otros buques de la División de Patrullado Marítimo, actuaba en forma coordinada con las Escuadrillas Aeronavales de Vigilancia y Exploración de la Base Aeronaval Almirante Zar y la Centralde Operaciones del Área Naval Atlántica, a fin de mantener la vigilancia sobre los buques pesqueros de distintas banderas operaban $n$ las proximidades a la milla 201 (ARGENTINA, 2010).

Ahora bien, si, por un lado, tomamos en consideración las orientaciones de política de Defensa establecidas en la normativa vigente desde la Ley de Defensa Nacional y su reglamentación correspondiente a los años 2006 y 2010; y, por otro lado, observamos que la Prefectura Naval tenía por misiones -entre otras- el cumplimiento de funciones de Seguridad interior y vigilancia de aguas jurisdiccionales argentinas(fluviales, lacustres, marítimas) en el marco de la Ley de Seguridad Interior. Se constata, pues, que las funciones de patrullado marítimo de unidades de la Armada tenían a superponerse con las tareas de la Prefectura Naval. ${ }^{36}$ En otros términos, la Armada desarrollaba tareas -en el marco de sus misiones subsidiarias- que se superponían con las de aquella Fuerzas de Seguridad federal: tareas

\footnotetext{
${ }^{34}$ La creación de la División de Patrullado Marítimo se produjo en coincidencia con una frustrada iniciativa del Ministerio de Defensa en el año 2001 -durante la gestión del ministro Horacio Jaunarena y con la presidencia de Fernando De la Rúasegún la cual se procuraba unificar los elementos de la Armada y la Prefectura Naval en una Marina Argentina, argumentando razones presupuestarias y de optimización en el empleo de los recursos de la Defensa nacional y la Seguridad interior. Dicha iniciativa, sin embargo, no alcanzó a consumarse debido a las fuertes resistencias que despertó en la dirigencia política con representación en el Congreso de la Nación -porque confundía la misión de "fuerzas de defensa nacional con policía de seguridad interior" - y en la propia conducción de la Prefectura Naval -que se resistía a perder la autonomía corporativa que había construido en democracia tras su separación de la Armada. Disponible http://www.pagina12.com.ar/2001/01-08/01-08-19/pag11.htm.

${ }^{35}$ La División de Patrullado Marítimo tenía entre sus funciones la patrulla dela jurisdicción marítima dela Argentina hasta las 200 millas; esto es, conforme a lo establecido por la Convención del Mar, a los Estad os ribereños les corresponde el "derecho exclusivo de exploración, conservación y explotación de los recursos naturales, renovables y no renovables, existentes en las aguas, lecho y subsuelo marino hasta las 200 millas, contadas desde las líneas de base a partir de las cuales se mide el ancho del mar territorial". (PERTUSIO, 2005, p.19). Cabe aclarar que las áreas marítimas sobre las cuales Argentina reivindicaba jurisdicción comprendían el mar territorial hasta las 12 millas, la zona económica exclusiva hasta las 200 millas. y la plataforma continental extendida hasta 350 millas medidas desde la línea de base. (DI VICENZO, 2008). ${ }^{36}$ Recordemos que hasta 1984 Prefectura Naval dependía de la Armada.
} 
marítimas, fluviales y de seguridad náutica, así como la prestación de servicios de búsqueda y rescate (el apoyo a la actividad en la Antártida era una misión subsidiaria de la Armada que no cumplía la Prefectura). ${ }^{37}$

En sí, dicha superposición no colisionaba con las orientaciones de las políticas y normas vigentes, toda vez que los medios de la Armada constituían recursos escasos a los que el Estado nacional, eventualmente, recurría para empeñarlos con vistas a hacer un uso racional de los medios públicos a su disposición. En la división de tareas a la que aludimos aquí, la Prefectura Naval cumplía funciones en aguas jurisdiccionales o aguas interiores(hasta las 12 millas) consideradas de uso soberano y en su zona contigua (12 millas más). El problema se presentaba cuando esas misiones subsidiarias pasaban a concentrar el centro de la planificación de actividades anuales de las unidades operativas y del personal de la Armada, como en el caso de la División de Patrullado Marítimo del Área Naval Atlántica.

Ciertamente, la Prefectura Naval no disponía (ni dispone) de medios suficientes para cumplimentar tales misiones. De allí que en un pedido de informes al Poder Ejecutivo Nacional efectuado por legisladores de la Cámara de Diputados de la Nación en 2012 -a propósito del accionar de la mencionada División- se consignaban las importantes tareas de vigilancia y control marítimo de sus unidades y las dificultades que enfrentaban para concretarlas:

\begin{abstract}
Recientemente, y como trascendió en diversas informaciones, una unidad de la Armada Argentina que presta servicio en la División de Patrullado Marítimo interceptó a dos buques pesqueros arrastreros de bandera española con registro en Pontevedra -el "Playa da Cativa" y "Playa de Sartaxens"- dentro de la Zona Económica Exclusiva bajo jurisdicción argentina. Los buques españoles y de otras banderas operan mediante licencias emitidas por la autoridad kelper, las cuales se reputan ilegales por nuestro país en el marco de la disputa bilateral con el Reino Unido. El buque argentino se encontraba en operaciones de identificación y conteo de la flota pesquera en el área adyacente a la Zona referida, cuando detectó a las embarcaciones extranjeras en plena faena y procedió a ordenarles que se retirasen del área bajo jurisdicción nacional, en la cual habían ingresado. Esa zona se superpone con el área de pesca establecida unilateral e ilegalmente por los kelpers luego de la
\end{abstract}

\footnotetext{
${ }^{37}$ Las misiones de la Prefectura Naval eran cumplir tareas de Guardacostas y Vigilancia de las aguas jurisdiccionales, Seguridad de la vida humana en el mar, Seguridady orden público, delitos y contravenciones, Seguridad portuaria, Auxilio a la justicia, Interdicción del tráfico de drogas, Inspección de buques, Registro Nacional de Buques, Registro y habilitación del personal navegante, Prevención de contaminación de las aguas, Control del transporte por agua de mercancías peligrosas, Investigación de acaecimientos de la navegación, reflotamiento de buques, Asistencia a las comunidades costeras.
} 
Guerra de Malvinas llamada Zona Externa de Conservación ("Falklands Outer Conservation Zone" o FOCZ). El gobierno usurpador protestó ante la medida argentina, como era de esperar, entendiendo que se había violado un área bajo su jurisdicción, la cual es absolutamente ilegítima [...] El territorio marítimo de la República Argentina comprende casi 3 millones de $\mathrm{km} 2$, y es equivalente a casi diez territorios de la Provincia de Buenos Aires o de la República Italiana. Se trata del ámbito por donde circula el $\mathbf{9 0 \%}$ del comercio exterior nacional. Su valor geoestratégico es inmenso, vinculado a la proyección sobre el Sector Antártico Argentino, a las Islas del Atlántico Sur y a una vinculación interoceánica mediante el Pasaje de Drake y el Estrecho de Magallanes. Se suma a esto la riqueza de recursos renovables y no renovables que yacen en nuestras aguas y el conflicto político-diplomático con insoslayables aspectos militares mantenido con el Reino Unido, que por supuesto supera a la mera concepción de "diferendo" o "controversia". Por estos motivos y con el acento puesto en la protección de la Soberanía Nacional, consideramos que el fortalecimiento de las capacidades de la Armada Argentina debe ser una prioridad estratégica en el marco de una política de Defensa seria, responsable; de cara a los actuales escenarios. Con el fin de conocer, en este caso, la situación operativa y presupuestaria de la DVPM que cumple un rol fundamental en la vigilancia de nuestros espacios marítimos y defensa de sus recursos, solicito el acompañamiento de mis pares al presente proyecto de resolución. ${ }^{38}$

El pedido de informe de los legisladores también destacaba la antigüedad de las unidades que integran la División - los avisos eran de la década de 1940, las corbetas de la de 1970, y la lancha patrullera de la de 1960-, el magro presupuesto destinado a la Defensa que restringía sobremanera los días de navegación y, en consecuencia, impedía asegurar la presencia del Estado argentino en la zona garantizando la protección de los recursos naturales y la soberanía nacional.

La evaluación del estado de situación formulada por los legisladores era coincidente con la de un oficial superior destinado en el Comando del Área Naval Austral entrevistado en el año 2008:

\footnotetext{
${ }^{38}$ Honorable Cámara de Diputados de la Nación. Expediente 6519-D2012. Trámite Parlamentario 124 del14/09/2012. Pedido de informe al PEN sobre la misión específica de la División de Patrullado Marítimo (DPM)de la Armada Argen tina y otras cuestiones conexas, presentado por los diputados nacionales Fernando Solanas, Jorge Cardelli, Alcira Argumedo, Fabián Rogel, Claudio Lozano y Nora Iturraspe.
} 
Faltan medios en la Armada para resguardar los intereses en el mar argentino. Esto no es una cuestión de interés de la Armada sino de todos los argentinos. Se patrulla. Hay presencia, pero no alcanza. La patrulla de las doscientas millas se hace con buques y con aviones. Los barcos pesqueros argentinos suelen estar en regla, pero los extranjeros muchas veces no. Y pescan en el límite de la jurisdicción, en la milla 201, a veces a fuera otras adentro de la jurisdicción argentina... Tuvimos problemas con la merluza el año pasado. También es indiscriminada la pesca del calamar. Se llevan nuestros recursos, porque los peces no saben de millas... Y una concentración de ciento cincuenta barcas pesqueros de gran porte es una ciudad enorme... Los avisos tienen por eso la misión de patrullar las doscientas millas de la zona económica exclusiva. (Cuaderno de Campo Negro, Armada 4, jul. 2008).

Cuando durante la "patrulla de las 200 millas" se detectaba un buque de pesca no autorizado o ilegal en aguas jurisdiccionales, se procedía a iniciar su seguimiento por el radar y se intentaba tomar contacto por radio. La dotación se aprestaba para el desarrollo de una operación de "visita, registro y captura-VRC". Cuando el pesquero era avistado se buscaba reconocer si había alguna actividad o presencia en su cubierta con los prismáticos y el comandante ordenaba el registro fílmico de la operación como potencial prueba judicial si se procedía a la captura. Asimismo se marcaba la derrota o recorrido del pesquero en la carta náutica y se procuraba identificar su matrícula. En el buque de guerra en que realizaba trabajo de campo etnográfico, esa operación "VRC" estaba cargo del oficial "jefe de cubierta"; unos doce suboficiales de diferentes jerarquías lo secundaban armados, con trajes y equipos especiales, prestos a abordar al pesquero sirviéndose de botes neumáticos con motor fuera de borda. Preventivamente se desenfundaba el cañón del buque y otros sistemas de armas emplazados en cubierta.

En tales circunstancias podían suceder las siguientes opciones: 1) que el pesquero se identificara y demostrara que contaba con la debida autorización de pesca; 2) que no se identificara y no se le pudiera dar alcance dentro de las aguas jurisdiccionales argentinas; 3 ) que no se identificara, se procediera a completar la operación de "visita, registro y captura" y se comprobara que se trababa de un buque que efectuaba pesca ilegal. Esta última situación era la que a todas luces resultaba más complicada para el comandante y la dotación del buque de guerra, pues debían proceder a la detención preventiva de la tripulación del pesquero y remolcarlo hasta un puerto en el continente para ponerlo a disposición de las Fuerzas de Seguridad y la Justicia federal. De modo tal que en esas circunstancias existía siempre el 
riesgo de tener que lidiar con la responsabilidad de cuidar y controlar una tripulación civil probablemente extranjera- durante la navegación hasta el puerto. ${ }^{39}$

Nos encontramos entonces con una situación en la que el Estado nacional empeñaba o pretendía empeñar el instrumento militar de la Defensa, fundamentalmente, en el cumplimiento de sus misiones subsidiarias. Veamos esta cuestión con más detalle. En la concepción de la Defensa nacional y la Seguridad interior vigentes en la Argentina en democracia, la protección de los recursos naturales en jurisdicción del Mar Argentino y el resguardo de la soberanía en el mismo era sin dudas una misión principal de las Fuerzas Armadas si las amenazas provenían de "agresiones de origen externo perpetradas por fuerzas armadas pertenecientes a otro/s Estado/s" ${ }^{40}$ Es por ello que las funciones de vigilancia y control en el mar -tales como la detección, persecución, abordaje, captura y entrega a la justicia de buques de pesca ilegal- eran una labor que se correspondía más propiamente con las misiones de una Fuerza de Seguridad federal como Prefectura Naval, en tanto que sólo eventualmente debían ser objeto de atención de la Armada como misiones subsidiarias.

Ahora bien ¿qué usos hacía el Estado nacional de esas dos agencias? Por un lado, inevitablemente reconocía que la Prefectura Naval no disponía de los medios necesarios para realizar amplia y sistemáticamente sus tareas de seguridad en aguas jurisdiccionales; y, por otro lado, asumía que la Armada poseía medios relativamente ociosos (esto último, entiéndase, sólo en tanto y en cuanto dirigentes políticos y funcionarios ministeriales no ponderaban debidamente el efectivo cumplimiento de su misión principal como instrumento militar naval de la Defensa).

Como consecuencia de ese estado de situación y de las percepciones acerca los instrumentos estatales de la Seguridad y la Defensa, las unidades de la División de Patrullado Marítimo terminaban empleándose centralmente en la concreción de unas misiones subsidiarias que - de facto- acababan siendo su misión principal, esto es, la misión que mayores recursos humanos y materiales, así como tiempos y esfuerzos, demandaba a sus componentes. Sin dudas era lícito y oportuno que el Estado nacional se sirviera de los recursos escasos que tenía a la mano en circunstancias excepcionales y/o empleado capacidades excedentes -como decía la legislación vigente- que no vulnerasen el logro de la misión principal de las Fuerzas Armadas; pero resultaba evidente que, de continuarse este uso de las unidades navales de superficie, se desperfila completamente la misión principal que debe tener una marina de guerra.

\footnotetext{
39 De hecho esta última situación ocurría infrecuentemente debido a que los pesqueros ilegales solían navegar más velozmente que los avisos de la División de Patrullado Marítimo y, posiblemente, los comandantes de estos últimos evaluaran con mucho detalle costos y beneficios de concretar la operación de "visita, registro y captura" hasta su súltimas instancias.

${ }^{40}$ Y no debe escapar al análisis el hecho de que el Atlántico Sur era y es un escenario estratégico internacional que cuenta con la presencia militar efectiva de potencias extra-regionales, siendo el asentamiento militar británico en las Islas Malvinas su evidencia más visible, pero no la única.
} 
Quiero insistir en este breve comentario que lo que se coloca como punto de discusión aquí no es la eficacia de la División de Patrullado Marítimo en el desempeño de sus funciones, sino su pertinencia con relación al marco político y jurídico de la Defensa y la Seguridad vigente en la Argentina en democracia, así como la racionalidad de continuar desviando el alistamiento, adiestramiento y sostenimien to de esos recursos humanos y materiales de las Fuerzas Armadas del logro de su misión principal o sustantiva. ${ }^{41}$ Asimismo esta cuestión tenía por correlato en la política de Seguridad y sus instrumentos la postergación de la decisión política de dotar a la Prefectura Naval de los medios indispensables para realizar adecuadamente su misión sustantiva.

\section{Conclusiones}

La disposición de un instrumento militar naval con capacidades efectivas para hacer valer la soberanía sobre el Atlántico Sur y la Antártida en el siglo XXI, constituye un desafío fundamental para que la Argentina pueda garantizar su presencia y control sobre ese extenso espacio marítimo y continental de importancia estratégica. Sin embargo, no parece estar en condiciones adecuadas para afrontar ese desafío. Analistas y actores sociales del sistema de Defensa argentino han señalado la acentuada depreciación de las capacidades militares de este país desde la apertura democrática de 1983 hasta el presente. Dicha situación se ha atribuido en unos casos a la intención de sectores de la dirigencia política de restar poder corporativo a las conducciones de las Fuerzas Armadas; y en otros debido a que -más ampliamente- el conjunto de la dirigencia política argentina percibe la inexistencia de amenazas militares externas inminentes, no pondera la necesidad estratégica de contar con un instrumento militar con capacidad de disuasión efectiva y, en consecuencia, concluye que los asuntos de la Defensa nacional carecen de cualquier prioridad en la agenda pública. Tal situación se ve agravada en el caso de la Armada debido a que -como se observara en documentos oficiales de esta Fuerza y del Ministerio de Defensa (ARMADA ARGENTINA, 2010; ARGENTINA, 2008) la Argentina es un país que posee un enorme frente marítimo, pero

\footnotetext{
${ }^{41}$ Tomando como presupuesto que en democracia es la dirigencia política constitucionalmente electa quien debe definir el por qué y para qué de una marina de guerra, es posible identificar -siguiendo al contraalmirante(R) Roberto Pertusioun repertorio de empleos posible (remarcamos, posible, no necesario, pues cada país determina qué debe y/o puede disponer en materia de Defensa): 1) operaciones ofensivas contra fuerzas navales enemigas; 2) operaciones defensivasofensivas ante la amenaza de fuerzas navales enemigas sobre las propias; 3) operaciones ofensivas contra las línea de comunicaciones marítimas enemigas; 4) operaciones defensivas de las líneas de comunicaciones marítimas propias; 5) operaciones ofensivas contra territorio enemigo; 6) operaciones defensivas en el territorio propio. De ese repertorio de operaciones este analista destaca que en el caso argentino sería preciso contar con una Armada en el siglo XXI en condiciones de asegurar operaciones navales del tipo de las consignadas con el número 2, 4 y 6. (PERTUSIO, 2005).
} 
cuya dirigencia política y sus ciudadanos históricamente ha tenido una débil conciencia de los recursos que deben resguarda en el mar.

En el desarrollo del artículo hemos reconocido procesos de reestructuración producidos en el diseño de fuerza de la Armada Argentina en el cambio del siglo XX al XXI con vistas a ajustar su configuración a las definiciones de la política de Defensa y la legislación vigente en democracia. Dicha reestructuración afectó su organización, funciones, dimensiones y despliegue. En el caso del componente de infantería de marina se destacó no sólo la reducción significativa en la cantidad de unidades y efectivos, sino también el desarrollo de funciones polivalentes efectuadas por su personal en realización con las misiones subsidiarias de las Fuerzas Armadas. Particularmente se llamó la atención sobre el hecho de que este componente de la Armada es socialmente reconocido por la dirigencia política más por su potencial empeñamiento en misiones de paz y tareas propias de la Defensa civil, que por sus capacidades para concretar operaciones anfibias requeridas por el sistema de Defensa nacional. En tanto que en el caso de los buques de guerra de la División de Patrullado Marítimo hemos enfocado la creciente relevancia asumida por las funciones de vigilancia y control de la pesca ilegal desempeñada por unidades de la Armada en el Atlántico Sur; cuestión que en sí misma no violenta el marco político y normativo vigente en democracia, pero que pone en evidencia el elocuente contraste existente entre las capacidades operativas relativamente más altas de las unidades de dicha División, en relación con la escasa o prácticamente nula operatividad de aquellas unidades que deberían empeñarse en ejercicios navales conjuntos y combinados decisivos para el logro de los objetivos propios de la misión principal de una marina de guerra concebida para atender amenazas estatales externas.

Por último, señalemos que de persistir este estado de situación, en la próxima década del siglo XXI la Argentina no sólo no estará en condiciones de disponer de un poder naval con capacidades de disuasión efectiva contra eventuales amenazas estatales externas del país; asimismo, en el escenario cooperación a nivel del Cono Sur y Suramericano no podrá garantizar la interoperabilidad con las fuerzas navales de otros países ni, muncho menos, proveer recursos al potencial diseño de un sistema de Defensa regional, tal lo previsto a nivel nacional desde la sanción de la Ley de Reestructuración de las Fuerzas Armadas en 1998 y a nivel regional por la Unión de Naciones Sudamericanas.

\section{Referências}

ALBARRACÍN, Santiago. La escuadra argentina en la Patagonia. Buenos Aires: Marymar, 1976. 
ARGENTINA. Ministerio de Defensa. Perspectiva Estratégica del mar y la Plataforma Continental de la Argentina. Buenos Aires: Ministerio de Defensa, 2008.

ARGENTINA. Ministerio de Defensa. Libro Blanco de la Defensa. Buenos Aires: Ministerio de Defensa, 2010.

ARMADA ARGENTINA. Infantería de Marina. Buenos Aires: Asociación de Oficiales Retirados de Infantería de Marina, 2005.

ARMADA ARGENTINA. Zonas de interés estratégico y geopolítico para la Nación: situación en el Atlántico Sur y en la Antártida. Buenos Aires: Instituto Universitario Naval, 2010.

DESTÉFANI, Laurio. El Alférez Sobral y la soberanía Argentina en la Antártida. Buenos Aires: Editorial Universitaria de Buenos Aires, 1978.

DI VICENZO, Andrés. El límite exterior de la plataforma continental. Revista de la Defensa, Buenos Aires, n. 2, p.31-43, 2008.

FREDERIC, Sabina; MASSON, Laura; SOPRANO, Germán. Fuerzas Armadas en democracia. Perspectivas de los militares argentinos sobre su reconocimiento. Rosario: Prohistoria, 2015.

LAFFERRIERE, Guillermo; SOPRANO, Germán. El Ejército y la Política de Defensa en la Argentina del siglo XXI. Rosario: Prohistoria, 2015.

MARTÍN, Daniel. Búsqueda y rescate en la Antártida. Patrulla Antártica Naval Combinada. Boletín del Centro Naval, Buenos Aires, n. 836, p.209-214, 2013.

MONTENEGRO, Germán. El marco normativo y doctrinario de la defensa nacional. Revista de la Defensa Nacional, Buenos Aires, n.1, p. 14-27, 2007.

OYARZÁBAL, Guillermo. Los marinos de la Generación del Ochenta. Buenos Aires: Emecé, 2005.

PERTUSIO, Roberto. Una marina de guerra ¿Para qué? Buenos Aires: Centro Naval, 1987.

PERTUSIO, Roberto. Diseño de una Armada posible para la República Argentina de los próximos 25 años. Buenos Aires: Centro Naval, 2005.

ROJAS, Isaac. Intereses argentinos en la Cuenca del Plata. Buenos Aires: Ediciones Libera, 1974.

ROJAS, Isaac; MEDRANO, Arturo. Argentina en el Atlántico, Chile en el Pacífico. Buenos Aires: Nemont Ediciones, 1978.

TRIADÓ, Enrique. Historia de la Base Naval Puerto Belgrano. Buenos Aires: Instituto de Publicaciones Navales, 1991. 


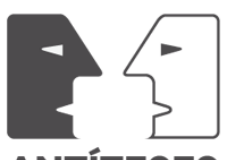

ANTÍTESES

UGARTE, José Manuel. Los conceptos jurídicos y políticos de la seguridad y la defensa. Buenos Aires: Plus Ultra, 2004.

VÁRNAGY, Tomás. Naciones Unidas y regionalismo: `Cruz del Sur', una fuerza de paz combinada argentino-chileno. Cuadernos de Marte, Buenos Aires, año 1, n 0, p.177-208, 2010.

VELÁZQUEZ PACHECO, Luis Hernán. Educación combinada entre las Armadas de Argentina y Chile: una propuesta para la interoperabilidad desde la perspectiva de la capacitación de los oficiales jefes. Buenos Aires: Escuela de Guerra Naval, Instituto Universitario Naval, 2010.

Recebido em 16/03/2016

Aprovado em 24/01/2017 